\title{
ГУМАНИТАРНЫЕ ПРОЕКТЫ
}

Овчаров А. О.

\author{
ИННОВАЦИОННЫЕ МЕГАПРОЕКТЫ \\ КАК ИНСТРУМЕНТ ГОСУААРСТВЕННОЙ \\ ПОАИТИКИ В НАУЧНО-ТЕХНИЧЕСКОЙ СФЕРЕ
}

\begin{abstract}
Аннотация. Предметом исследования являются особенности функиионирования инновачионных мегапроектов в научной сфере России. Поставлена задача определить контуры государственной научно-технической политики через создание и поддержку крупных научно-исследовательских проектов. Особое внимание уделяется проблемам финансирования и оценки эффективности российской науки, возникшим в условиях кризиса 2014 г. С критических позиций рассмотрены механизмы государственного участия в таких проектах, как «Сколково» и начиональные исследовательские университеты. Ааны характеристики особых экономических зон техниковнедренческого типа как важного инструмента стимулирования инновачионной активности. В статье применялись такие общенаучные методы, как анализ и синтез, индукиия и дедукиия. В отночении данных об индикаторах инновачионной активности в научно-технической сфере использовались частнонаучный метод статистической группировки. В статье обосновано, что использование термина «мегапроект» возможно не только в отночении крупных инвестиционных проектов, но и в отночении науки и государственной политики в научно-технической сфере. Выделены критерии отнесения проекта к мегапроекту и показана применимость этих критериев для инновачионных проектов в научной сфере. Впервые проведен сравнительный анализ двух редакций государственной программы РФ «Развитие науки и технологий» на 2013-2020 годы. Выявлены сокращение объемов государственного финансирования данной программы, корректировка ее целевых индикаторов, а также снижение требований к ряду параметров научно-исследовательской и инновационной деятельности. Особым вкладом автора в исследование темы является то, ито раскрыта роль трех мегапроектов в инновачионном развитии страны: проект «Сколково», особые экономические зоны технико-внедренческого типа, начиональные исследовательские университеты. Сделан вывод, что, несмотря на экономические трудности, Россия стремится подтвердить свой статус мировой научной державы с высокой степенью международного сотрудничества.
\end{abstract}


Ключевые слова: мегапроект, инновационне развитие, научно-техническал сфера, индикаторы, государственная программа, фундаментальные исследования, финансирование, особые экономические зоны, национальные исследовательские университеты, интеграция.

Review. The subject of the research is the peculiarities of functioning of innovative megaprojects in the scientific sphere of Russia. The objective is to determine the shape of the state scientific and technical policy through the establishment and support of major research projects. Special attention is paid to the problems of financing and evaluation of the effectiveness of Russian science, that emerged during the crisis of 2014. The mechanisms of state participation in such projects as Skolkovo and National research universities are critically considered. The characteristics of the special economic zones of innovation type as an important tool for encouraging innovation activity are presented. The article used such methods as scientific analysis and synthesis, induction and deduction. For the analysis of data on indicators of innovative activity in science and technology the method of statistical grouping is used. In the article it is proved, that the term "megaproject" can not only be used for major investment projects, but also for science and public policy in science and technology. The criteria for the megaproject are identified and the applicability of these criteria for innovative projects in the field of science is showed. The comparative analysis of the two editions of the state program of the Russian Federation "The development of science and technology" in the 2013-2020 periods is presented for the first time. The decrease in publicfunding for the program, correcting its target indicators, as well as the reduced requirements to some parameters of research and innovation is identified. The special contribution of the author to the study is the description of the role of three megaprojects (Skolkovo, Innovation Zones, National research universities) in innovative development of the country. It is concluded that despite the economic difficulties, Russia is seeking to reaffirm its status as the world scientific power with a high degree of international cooperation.

Keywords: funding, fundamental researches, state program, indicators, sphere of science and technology, innovative development, megaproject, special economic zones, National research universities, integration.

$\mathrm{T}$ раАиционно под термином «мегапроект» понимается совокупность инвестиционных проектов, объединенных оАной целью, ресурсной базой и сроком реализации. Есть, как минимум, Ава критерия отнесения проекта к мегапроекту: объемы финансирования и социально-экономическая значимость ${ }^{[1]}$. СреАи экономистов существуют различные мнения по поводу количественных значений стоимости мегапроекта. Как правико, устанавливается планка в 1 млрд. Аолм. и выше. Что касается социально-экономической значимости, то такой проект Аолжен иметь общегосударственное значение, носить межотраслевой характер и способствовать качественно новому развитию региона или Ааже всей страны.

В РФ в первую очереАь мегапроекты стали реализовываться в сырьевом секторе экономики в виде большого класса межотраслевых

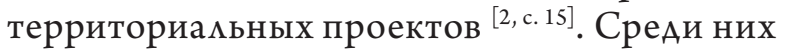
Аоминировали мегапроекты топмивно-энергетического комплекса (Ямах, Сахалин, Восточно-Сибирский нефтегазовый компкекс) и метамлургии. Сегодня получими распро- странение инфраструктурные мегапроекты, например, БАМ-Транссиб, высокоскоростная магистраць Москва-Казань, Центрамьная кольцевая автомобильная дорога. По мнению министра транспорта России М. Соколова, «эти проекты призваны оживить не только экономику регионов, но и в целом стимулировать экономический рост страны» ${ }^{[3]}$. Особое место среАи мегапроектов занимают проекты, приуроченные к значимым мировым событиям, проходящим в России (ОАимпийские игры, Чемпионат мира по футболу, саммит АТЭС и т.п. ).

Вместе с тем, термин «мегапроект» применим и к науке и к государственной политике в научно-технической сфере. СозАание атомной бомбы (манхэттенский и курчатовский проекты), Большой аАронный колайдер, космические проекты - все это примеры научных мегапроектов, требующих громадных ресурсов и имеющих большое значение Аля инновационного развития страны.

Опредемение термина «мегапроект» в контексте государственного управления российской наукой Аано в приможении 4 
Стратегии развития науки и инноваций в РФ на период до 2015 года. Согласно Аанной Стратегии поА мегапроектом понимается «комплекс взаимоувязанных по ресурсам, исполнителям и срокам осуществления мероприятий, который направмен на Аостижение необходимого уровня национальной безопасности, получение экономического эффекта, имеющего значение на уровне экономики в целом или крупных секторов экономики» ${ }^{[4]}$. ГАавной экономической цемью таких мегапроектов явмяется усимение конкурентоспособности российских преАприятий, произвоАящих наукоемкую проАукцию, на внутреннем и внешнем рынках. Мегапроекты явцяются механизмом стимулирования инновационной активности, который обеспечивает трансформацию результатов научных исследований в конкурентоспособную наукоемкую продукцию.

В 2014 г. была принята государственная программа РФ «Развитие науки и технологий» на 2013-2020 годы (утвержАена постановлением Правительства РФ от 15.04.2014 г., № 301), в которой мегапроекты в сфере науки преАставлены в виде шести подпрограмм и оАной Аействующей феАеральной целевой программы. Объемы бюАжетного финансирования Аанной программы за весь периоА ее Аействия Аолжны составить 1,48 трлн. руб. При этом слеАует отметить, что первоначамьный вариант программы, утвержденный еще в 2012 г. (распоряжение Правительства от 20.12.2012 г., № 2433-p) преАполага более крупные масштабы государственной поААержки: за весь периоА из бюАжета преАполагалось направить 1,6 трлн. руб. Аругими словами, сегодня мы имеем $10 \%$-е сокращение государственного финансирования российской науки. Это вписывается в общую могику современной бюАжетной политики, когАа происходит сокращение госуаарственных расходов, вызванное негативными последствиями событий 2014 г. (экономические санкции, Аевамьвация рубля, низкие цены на нефть и т.п. ).

Вместе с тем, неблагоприятная экономическая конъюнктура и очевидные изоляционистские тенденции в 2014-2015 гг. не отменими ранее поставменную цемь интеграции российской науки в глобальную инновационную систему. Из выступмений руковоАства страны и различных документов следует, что, несмотря на экономические труаности, Россия стремится подтверАить свой статус мировой научной Аержавы с высокой степенью межАународного сотруАничества. Аця этого среАи целевых инАикаторов программы, т.е. параметров, по которым оценивается ее результативность, есть такие, как количество и цитируемость российских авторов в межАународных научных журналах, коэффици-

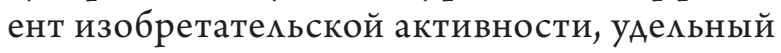
вес исследователей в возрасте Ао 39 мет и т.А.

ОАна из шести поАпрограмм («Фунааментальные научные исследования»), будучи самой крупной по объему финансирования (869,6 ммрА. руб., т.е. более половины от всех бюАжетных среАств программы), призвана обеспечить высокий уровень российских исследований и их результатов, соответствующих мировым стандартам. Реализация подпрограммы, по мнению разработчиков, будет стимулировать «развитие каАрового потенциа а науки, эффективное восполнение и повышение квалификации научно-исследовательских кадров, усимение мотивации работников, повышение мобимьности ученых, расширение возможностей профессионацьной самореализации талантливой молодежи в научной сфере».

Анализ Авух реАакций программы РФ «Развитие науки и технологий» на 2013-2020 годы, кроме снижения финансирования, позволил выделить еще Ава интересных момента. Во-первых, сАелана существенная корректировка самой системы показателей (целевых ориентиров) - введены новые показатели с одновременным искцючением старых. Так, в подпрограмме «Фундаментальные научные исследования т только три показателя имеются в обоих вариантах. Они представлены в табл. 1, причем показаны нами в сравнении: числитель отражает значение индикатора в Аействующей реАакции госуАарственной программы, а знаменатель - в первоначамьной реАакции 2012 гоАа. При этом в Аанную подпрограмму добавлены 4 новых индикатора, а искиючены 2 старых, связанных с уровнем госуаарственных затрат на НИОКР - 
Таблица 1. Целевые индикаторы подпрограммы «Фундаментальные научные исследования» государственной программы РФ «Развитие науки и технологий» на 2013-2020 годы

\begin{tabular}{|l|l|l|l|l|}
\hline Индикатор & $\mathbf{2 0 1 4}$ & $\mathbf{2 0 1 6}$ & $\mathbf{2 0 1 8}$ & $\mathbf{2 0 2 0}$ \\
\hline \begin{tabular}{|l|l|l|l|} 
Число публикаций российских авторов в научных журналах, индексируемых \\
в базе данных Sсориs (в расчете на 100 исследователей), единиц
\end{tabular} & $\frac{10,5}{9,1}$ & $\frac{10,9}{10,0}$ & $\frac{11,3}{10,5}$ & $\frac{11,6}{13,0}$ \\
\hline $\begin{array}{l}\text { Число цитирований в расчете на 1 публикацию российских исследователей } \\
\text { в научных журналах, индексируемых в Web of Science, единиц }\end{array}$ & $\frac{1,45}{2,9}$ & $\frac{1,54}{3,4}$ & $\frac{1,66}{3,7}$ & $\frac{1,8}{4,0}$ \\
\hline Средний возраст исследователей, лет & $\frac{47,7}{47}$ & $\frac{46,8}{45}$ & $\frac{45,8}{44}$ & $\frac{44,9}{43}$ \\
\hline
\end{tabular}

кмючевым, на наш взгляА, финансово-экономическим показателем, характеризующим инновационную активность.

Во-вторых, изменены требования, часто весьма существенно, к ряду параметров наУчно-исслеловатемьской и инновационной Аеятемьности. Причем это касается не только публикационной активности (из табл. 1, например, винно резкое снижение требований к цитируемости пубмикаций российских ученых в межАународных рейтинговых журнамах), но и Аругих критериев эффективности научно-инновационной Аеятельности, заложенных в Аругие подпрограммы. Например, к 2020 г. пороговые значения коэффициента изобретатемьской активности (число заявок на изобретения, поданных в РФ в расчете на 10 тыс. чел. населения страны) снижено с 2,8 Ао 2,4, а Аоли среАств, полученных от выпомнения научной и научно-технической Аеятельности, в общем объеме среАств веАущих российскихуниверситетов - с 48,3\% Ао $25 \%$.

Следует отметить, что Ао принятия госуАарственной программы РФ «Развитие науки и технологий» на 2013-2020 годы в нашей стране реализовывались мегапроекты, которые были представмены в форме федеральных целевых программ (ФЦП). Новая программа вкАючима в качестве составной части только оАну из них - ФЦП «ИсслеАования и разработки по приоритетным направлениям развития научно-технологического комплекса России на 2014-2020 годы». Аругие ФЦП, тесно связанные с наукой и высокими техномогиями (например, «ПодАержание, развитие и использование системы ГАОНАСС на 20122020 годы» ими «ЯАерные энерготехнологии нового покомения на период 2010-2015 годов и на перспективу Ао 2020 года») являются самостоятемьными мегапроектами.
Обратим внимание также на то, что в 2008 г. была принята ФЦП «Научные и научно-педагогические кадры инновационной России» на 2009-2013 годы. Ее принятие Аиктовалось необходимостью каАрового укрепления госуаарственного сектора науки и высшего образования. ПоскомькуАанная программа обнаружима высокую востребованность в научной и образовательной среле, то в 2013 г. была принята аналогичная программа на срок 2014-2020 гг. с общим объемом финансирования бомее 200 млрА. руб. В программу быми Аобавлены новые направления, в частности, подАержка национамьных исследоватемьских университетов, а также новые показатеми и инАикаторы. ОАнако мы вынужАены констатировать, что постанов ением Правитемьства РФ № 1094 от 23.10.2014 г. принято решение о досрочном (с 1 января 2015 г.) прекращении реализации данной программы.

Если в качестве гмавного критерия отнесения проекта в научно-инновационной сфере к мегапроекту взять его общую стоимость (объемы финансирования) в размере более 1

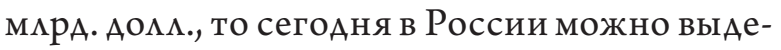
$\Lambda$ ить еще три виАа инновационных мегапроектов: проект «Сколково», особые экономические зоны технико-внедренческого (инновационного) типа (ОЭЗ ТВТ), национацьные исслеАовательские университеты. При этом очевиАно, что кажАый из них вкмючает в себя отдельные проекты, которые не могут считаться мегапроектами в симу своего частного характера и не превышения планки в 1 млрА. Аом.. ОАнако вместе они образуют систему, которая работает на общих принципахи преАполагает еАиный комплекс мероприятий.

Так, проект «Сколково»- созАанный близ Москвы научно-технологический комплекс по разработке и коммерциамизации 
новых технологий: энергетических, яАерных, космических, меАицинских, компьютерных. Госуаарственные ресурсы направляются на развитие инфраструктуры (в том числе научной), а также на разработку проектной Аокументации по некоммерческим объектам. В трехлетнем федерацьном бюАжете (2011-2013 гг.) объемы финансирования быми заложены в размере, превышающем 50 мирА. руб. По состоянию на конец первого покугоАия 2014 г. общее число резилентов проекта составимо 1065 (всего на получение статуса участника бымо подано 6108 заявок). ОАобрено 248 грантов на общую сумму 9,5 мира. руб. Развивается инфраструктура, формируется эффективная система управления, совершенствуется PR и т.A.

Признавая важность и актуацьность созАания современного научного комплекса, Учитывая опыт созАания подобных комплексов в Аругих странах, существует большое число критических сужАений По повоАу реамизации проекта. Речь идет и о неудачном территориальном расположении, и об отсутствии четкой стратегии развития, и о высоких рисках самомиквидации компаний-участников (стартапов), и о коррупционных схемах, и о высокихаАминистративных расходах. Так, по мнению Ю. Аммосова, проект «Сколково» ориентирован на модель бизнеса, носящую образное название «лучшая мышеловка» («если построить кучшую в мире мышеловку, то мыши туда придут сами») [5]. Аанная модемь основана на выстраивание рынка поА продукт и описывается схемой: придумать, разработать, протестировать, созАать, проанализировать рынок и затем продать. ОАнако очень часто резумьтатом такого подхода становимась ситуация, при которой результат труаа ученых и инженеров не помьзовался спросом у покупателей. СегоАня на Западе попукярна Аругая модемь, в которую вписать проект «Сколково» является проблематичным, - моде ь «открытия покупате яя. Она основана на сложной многоступенчатой и постоянной работе с будущими потребителями с самого начама разработки продукта. ГАавное в этой модеми - использование современных ПоАходов ПроАуктового маркетинга, т.е. выстраивание продукта под рынок, а не наобо- рот, рынка поА ПроАукт. Это Аолжно снизить неэффективность использования ресурсов и серьезно повысить шансы на успех и инновационного продукта, и самого преАприятия.

Кроме того, проект «Сомково» часто сравнивают с камифорнийской «Симиконовой Аолиной $>$ или с инАийским Бангамором - крупнейшим в стране научным и индустриальным центром, выпускающим продукцию машиностроения, электроники, аэрокосмической отрасли, телекоммуникационного оборуаования и оборонной промышленности. ОАнако, подобные сравнения, по мнению ряда ученых, некорректны. Например, «Симиконовая Аолина» размещена на гораздо большей территории, чем Скомково. Она не была создана решением сверху, а созАава Аась эволюционно, причем не на пустом месте, а вокруг СтенфорАского университета, который и бым основным источником инновационных илей. В этом смысле к «Симиконовой Аолине» более близки отечественные наукограды и акаАемгородки, сложившиеся еще в советский периоА. Что касается Бангамора, то большинство реализуемых там инноваций не имеет никакого отношения к экономическим проблемам страны. По мнению Б. Кагармицкого, «запаАные корпорации используют мозги хорошо образованных, но низко опмачиваемых специамистов, чтобы экономить Аеньги, решая зАесь второстепенные заАачи по собственным исследоватемьским программам. Значитемьная часть инАийских ученых, задействованных в этих программах, признается, что Ааже не знает об их целях и смысле» ${ }^{[6]}$. При этом хорошо зарекомендовавшие себя эксперты переезжают в университеты Англии и США, поскольку инАийская «Си$\Lambda$ иконовая Аолина» бцагодаря намаженной системе интернационацьных связей и вкмюченности в межАународное разАеление труаа является сегоАня крупным каналом утечки мозгов из страны. Само же правитемьство вкцаАывает Аеньги в технологические проекты, никак не связанные с жизнью простых мюдей. Такую ситуацию хорошо обрисова инАийский журналист: «мы можем запускать в космос спутники, но не можем, технически не можемпровести канализацию в небольшом городе. На местном уровне недоступны про- 
Таблица 2. Характеристики ОЭЗ ТВТ

\begin{tabular}{|c|c|c|c|c|}
\hline \multirow[t]{2}{*}{$\begin{array}{l}\text { Наименование, } \\
\text { расположение }\end{array}$} & \multirow[t]{2}{*}{$\begin{array}{l}\text { Площадь } \\
\text { территории, га }\end{array}$} & \multicolumn{2}{|c|}{$\begin{array}{l}\text { Государственные } \\
\text { инвестиции, млрд. руб. }\end{array}$} & \multirow[t]{2}{*}{ Приоритетные направления развития } \\
\hline & & План & $\begin{array}{l}\text { Факт } \\
\text { (на 01.09.2014) }\end{array}$ & \\
\hline $\begin{array}{l}\text { ОЭЗ ТВТ } \\
\text { «Зеленоград» } \\
\text { (г. Москва) }\end{array}$ & 145,8 & 32,56 & 7,2 & $\begin{array}{l}\text { Микроэлектроника, энергосберегающие } \\
\text { технологии, биотехнологии, информацион- } \\
\text { ные и коммуникационные технологии }\end{array}$ \\
\hline $\begin{array}{l}\text { ОЭЗ ТВТ «Дубна» } \\
\text { (Московская } \\
\text { область) }\end{array}$ & 187,7 & 17,17 & 8,3 & $\begin{array}{l}\text { Информационные, ядерно-физические } \\
\text { и нанотехнологии, био- и медицинские } \\
\text { технологии, композиционные материалы, } \\
\text { проектирование сложных технических } \\
\text { систем }\end{array}$ \\
\hline $\begin{array}{l}\text { ОЭЗ ТВТ «Санкт- } \\
\text { Петербург» (г. Санкт- } \\
\text { Петербург) }\end{array}$ & 129,4 & 17,87 & 8,1 & $\begin{array}{l}\text { Информационные технологии и телеком- } \\
\text { муникации, фармацевтика и медицинские } \\
\text { технологии, энергоэффективность, точное } \\
\text { приборостроение }\end{array}$ \\
\hline $\begin{array}{l}\text { ОЭЗ ТВТ «ТОмСК» } \\
\text { (г. Томск) }\end{array}$ & 207,0 & 16,17 & 7,1 & $\begin{array}{l}\text { Информационные технологии и электро- } \\
\text { ника, нанотехнологии и новые материалы, } \\
\text { медицина и биотехнологии, ресурсосбере- } \\
\text { гающие технологии }\end{array}$ \\
\hline $\begin{array}{l}\text { ОЭЗ ТВТ «Иннопо- } \\
\text { лис» (Республика } \\
\text { Татарстан) }\end{array}$ & 294,0 & н/д & Н/Д & $\begin{array}{l}\text { Информационно-коммуникационные тех- } \\
\text { нологии, электронные и нанотехнологии, } \\
\text { био- и медицинские технологии }\end{array}$ \\
\hline
\end{tabular}

стейшие техномогии, нет специалистов, и никто и рупии не потратит на такие мемочи».

Задача коммерциамизации инновационных технологий ставится не только в Сколково, но и в Аеятельности ОЭЗ ТВТ. Известно,

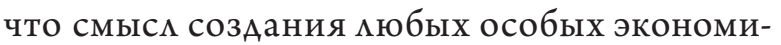
ческих зон закмючается мибо в стремлении

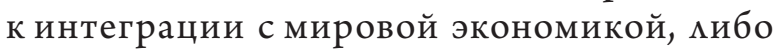
в необхоАимости Развития отАеАьных виАов Аеятельности, имеющих бомьшое значение Аля национамьного хозяйства. Второе обстоятемьство стало причиной созАания пяти ОЭЗ ТВТ.

Не вааваясь в технологию созАания и механизмы функционирования ОЭЗ ТВТ, отметим только три основных принципа их работы:

- территориальная мокамизация;

- госуаарственно-частное партнерство;

- налоговые и иные мьготы (преференциамьный режим).

Так, согласно федерамьному закону «Об особых экономических зонах в Российской Федерации (№ 116-Ф3 от 22.07.2005, с послеАующими изменениями и Аополнениями) технико-внедренческие особые зоны созАаются не более чем на трех участках тер- ритории, общая площаАь которых составляет не более 4 км². СреАи налоговых мьгот Аля резидентов можно выдемить такие мьготы, как нумевые ставки по налогу на имущество, налогу на землю и транспортному налогу. Компании-инвесторы всех особыхзон помьзуются режимом свободной таможенной зоны, согласно которому иностранные товары размещаются и используются в пределах территории ОЭЗ без упматы таможенных пошиин и НАС, а также без применения к указанным товарам запретов и ограничений экономического характера. Кроме того, инвесторы помьзуются такими неналоговыми преференциями, как мьготные ставки при аренде помещений, мьготные механизмы креАитования, венчурное финансирование проектов и т.А.

В табл. 2 преАставцены отдемьные характеристики ОЭЗ ТВТ, взятые нами из Аанных официамьного сайта ОЭ3 [7]. Совокупный объем только государственныхзапланированных инвестиций превышает 80 ммрА. руб., что позвомяет отнести проект созАания техниковнеАренческих особых зон к чиску инновационных мегапроектов научной сферы.

В инновационную модемь организации науки сегоАня вписывается еще оАин мега- 
проект - созАание национальных исслеАовательских университетов (НИУ) и государственная поААержка веАущих университетов с цемью повышения их конкурентоспособности среАи веАущих мировых научно-образоватемьных центров. Этот мегапроект можно расценивать как шаг, меняющий традиционную модемь российской науки и приближающий ее к запаАной модели, в которой практически отсутствует академический сектор науки, посколькувсе исследования сконцентрированы в рамках университетских центров без вылемения самостоятемьных структур, подобных PAH.

В результате конкурсного отбора статус НИУ сегоАня имеют 27 университетов (Московский госуаарственный технический университет им. Н.Э. Баумана, Нижегородский госуаарственный университет им. Н. И. Аобачевского (ННГУ), Пермский госуаарственный университет, Государственный университет - Высшая школа экономики и Ар.). Некоторые из них получими Аамьнейшую госуАарственную подАержку в рамках реализации плана мероприятий по вхожАению к 2020 г. не менее пяти российских университетов в первую сотню веАущих мировых университетов. Эта задача быма поставлена Президентом РФ в 2012 г. ПобеАившие вузы в кратчайшие сроки разработами Аорожные карты, в которых обозначими цемевые ориентиры. Например, ННГУ в качестве таковых виАит вхожАение в Аиапазон 91-140 кучших вузов мира (по версии рейтинга QS), троекратный рост количества публикаций, индексируемых Web of Science и Scopus, увемичение Аоли иностранных преподавателей и студентов и т.п. ${ }^{[8]}$. Фи- нансирование Аанной программы ННГУ за период 2013-2020 гг. Аолжно составить 7386,88 ммн. руб.

Принцип интеграции вузовского образования и научных исследований, который в России реализуется через созАание НИУ, очень часто становится преАметом критики. Суть этих замечаний своАится к слеАующему простому тезису: главная задача вузов это обучение студентов, а не осуществление научно-исследовательской Аеятельности. К тому же Россия имеет многовековые траАиции разделения науки и образования: за науку «отвечает» акаАемический сектор, за образование - вузы.

На европейском уровне многие эксперты также высказывают опасения в том, что эффективность науки не может быть повышена только за счет расширения вузовской научно-исследоватемьской составляющей. В Ао-

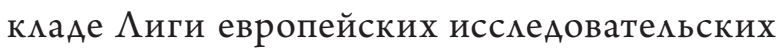
университетов отмечено, что бцагодаря этому расширению «наука может оказаться врагом высшего образования, а не его Аополнением», что немьзя рассматривать университеты как «супермаркеты, продающие модумьные проАукты $\gg$ [9, с. 151].

ОчевиАно, что справеАливость того ими иного мнения покажет только время. В настоящее время при всех сложностях экономической ситуации российская наука стремится найти новые институты, соответствующие современным инновационным потребностям национамьной экономики и развития общества и учитывающие отечественный и межАународный опыт организации научных исследований и внеАрения исслеАоватемьских разработок в практику.

\section{БИБАИОГРАФИЯ}

1. Мегапроекты против рецессии. URL: http://kommersant.ru/doc/2303944.

2. Пцяскина Н.И., Харитонова В.Н. Стратегическое планирование межотраслевых ресурсных мегапроектов: методология и инструментарий // Пробмемы прогнозирования.2013. — № 2.— C. 15-27.

3. Инвестфорум в Сочи сегодня обсужаает российские мегапроекты. URL: http://gigabaza. $\mathrm{ru} / \mathrm{doc} / 117 . \mathrm{html}$.

4. Стратегия развития науки и инноваций в Российской ФеАерации на периоА Ао 2015 года. URL: http://base.consultant.ru/cons/cgi/online.cgi?req=doc; base=LAW; n=101907/.

5. Аммосов Ю. Инновации: Сколковская мышемовка // Ведомости. - 2010.— № 72(2590) от 22.04.2010. 
6. Кагарлицкий Б. «Танцующие» мосты на пути в Сколково. URL: http://www.stoletie.ru/ tekuschiiy_moment/tancujushhije_mosty_na_puti_v_skolkovo_2010-07-02.htm.

7. Технологический тип OЭ3. URL: http://www.russez.ru/oez/innovation/.

8. Повышение конкурентоспособности ННГУ им. Н. И. Аобачевского среАи веАущих мировых научно-образовательных центров. URL: http://www.unn.ru/ranking.html?tab=2.

9. Варшавский А. Проблемы науки и ее результативность // Вопросы экономики. — 2011.— № 1.- С. 151-157.

10. ЕАронова В.Н., Овчаров А. О. Содержание, структура и специфические особенности науки как особого виАа Аеятемьности // Экономический анализ: теория и практика. - 2013. № 2.— C. 2-14.

11. ЕАронова В.Н., Овчаров А. О. Государственное управление научной деятельностью // Экономический анализ: теория и практика.— 2013.— № 7.- С. 2-15.

12. Кулешова Е.А. Роль институтов регионального преАставительства в процессе формирования госуАарственной инновационной политики // Юридические исслеАования.2014.- 9. - C. 1-9. DOI: 10.7256/2409-7136.2014.9.13026. URL: http://www.e-notabene. $\mathrm{ru} / \mathrm{lr} /$ article_13026.html

13. Знаменский А. Ю. Государство и гражАанское общество в процессе формирования приоритетов госуАарственной научно-технической политики // Социодинамика.— 2013. 10._ C. 1-17. DOI: 10.7256/2409-7144.2013.10.9489. URL: http://www.e-notabene.ru/pr/ article_9489.html

14. Овчаров А. О. Расходы на НИОКР как индикатор экономической безопасности // Национацьная безопасность / nota bene. - 2014. - 3. - C. 432-437. DOI: 10.7256/20738560.2014.3.11467.

15. Знаменский А. Ю. К вопросу о применении системно-Аинамического подхода к исслеАованию процессов формирования и реализации госуАарственной научно-технической помитики // Социодинамика. - 2014._- 7.—C. 50-63. DOI: 10.7256/2409-7144.2014.7.12801. URL: http://www.e-notabene.ru/pr/article_12801.html

16. Ю.В. Волокитина Порядок реализации госуАарственной инновационной политики путём использования правового потенциала отечественных ОЭЗ // Тренды и управление.2013. - 2. - C. 236-240. DOI: 10.7256/2307-9118.2013.2.5166.

17. Г. Ф. Галиева Макроэкономические предпосымки и факторы развития инновационной экономики // Национамьная безопасность / nota bene. - 2011. - 6. - C. 78-83.

18. М. В. Макарова Актуацьные проблемы инновационного развития России. Стратегия 2020 // Помитика и Общество.-2011.-9.- С. 4-10.

19. Фрумина С. В., Журавлева Т. А. Зарубежный опыт финансирования научных исследований и разработок // Намоги и налогообложение._-2014._ 8. - C. 758-765. DOI: 10.7256/18128688.2014.8.12715.

\section{REFERENCES (TRANSLITERATED)}

1. Megaproekty protiv retsessii. URL: http://kommersant.ru/doc/2303944.

2. Plyaskina N. I., Kharitonova V.N. Strategicheskoe planirovanie mezhotraslevykh resursnykh megaproektov: metodologiyaiinstrumentarii // Problemy prognozirovaniya.-2013.—№ 2.—S. 15-27.

3. Investforum $\mathrm{v}$ Sochi segodnya obsuzhdaet rossiiskie megaproekty. URL: http://gigabaza.ru/ doc/117.html.

4. Strategiya razvitiya nauki i innovatsii v Rossiiskoi Federatsii na period do 2015 goda. URL: http:// base.consultant.ru/cons/cgi/online.cgi?req=doc; base=LAW; n=101907/.

5. Ammosov Yu. Innovatsii: Skolkovskaya myshelovka // Vedomosti.— 2010.— № 72(2590) ot 22.04.2010.

6. Kagarlitskii B. 'Tantsuyushchie' mosty na puti v Skolkovo. URL: http://www.stoletie.ru/ tekuschiiy_moment/tancujushhije_mosty_na_puti_v_skolkovo_2010-07-02.htm. 
7. Tekhnologicheskii tip OEZ. URL: http://www.russez.ru/oez/innovation/.

8. Povyshenie konkurentosposobnosti NNGU im. N.I. Lobachevskogo sredi vedushchikh mirovykh nauchno-obrazovatel'nykh tsentrov. URL: http://www.unn.ru/ranking.html?tab=2.

9. Varshavskii A. Problemy nauki i ee rezul'tativnost' // Voprosy ekonomiki.— 2011.— № 1.— S. 151-157.

10. Edronova V.N., Ovcharov A. O. Soderzhanie, struktura i spetsificheskie osobennosti nauki kak osobogo vida deyatel'nosti // Ekonomicheskii analiz: teoriya i praktika.—2013.—№ 2.— S.2-14.

11. Edronova V.N., Ovcharov A. O. Gosudarstvennoe upravlenie nauchnoi deyatel'nost'yu // Ekonomicheskii analiz: teoriya i praktika.—2013.— № 7.- S. 2-15.

12. Kuleshova E.A. Rol' institutov regional'nogo predstavitel'stva v protsesse formirovaniya gosudarstvennoi innovatsionnoi politiki // Yuridicheskie issledovaniya. - 2014. - 9._ C. 1-9. DOI: 10.7256/2409-7136.2014.9.13026.URL: http://www.e-notabene.ru/lr/article_13026.html

13. Znamenskii D. Yu. Gosudarstvo i grazhdanskoe obshchestvo v protsesse formirovaniya prioritetov gosudarstvennoi nauchno-tekhnicheskoi politiki // Sotsiodinamika. - 2013. - 10. - C. 1-17. DOI: 10.7256/2409-7144.2013.10.9489. URL: http://www.e-notabene.ru/pr/article_9489.html

14. Ovcharov A. O. Raskhody na NIOKR kakindikator ekonomicheskoi bezopasnosti // Natsional'naya bezopasnost' / nota bene.-2014. - 3. - C. 432-437. DOI: 10.7256/2073-8560.2014.3.11467.

15. Znamenskii D. Yu. Kvoprosu o primenenii sistemno-dinamicheskogo podkhoda k issledovaniyu protsessov formirovaniya i realizatsii gosudarstvennoi nauchno-tekhnicheskoi politiki // Sotsiodinamika.—2014.-7.—C.50-63.DOI: 10.7256/2409-7144.2014.7.12801. URL: http:// www.e-notabene.ru/pr/article_12801.html

16. Yu.V. Volokitina Poryadok realizatsii gosudarstvennoi innovatsionnoi politiki putem ispol'zovaniya pravovogo potentsiala otechestvennykh OEZ // Trendy i upravlenie. - 2013._-2.- C.236-240. DOI: $10.7256 / 2307-9118.2013 .2 .5166$.

17. G.F. Galieva Makroekonomicheskie predposylki i faktory razvitiya innovatsionnoi ekonomiki // Natsional'naya bezopasnost' / nota bene. - 2011. - 6.- C. 78-83.

18. M.V. Makarova Aktual'nye problemy innovatsionnogo razvitiya Rossii. Strategiya 2020 // Politika i Obshchestvo. - 2011.-9.- C. 4-10.

19. Frumina S. V., Zhuravleva T.A. Zarubezhnyi opyt finansirovaniya nauchnykh issledovanii i razrabotok // Nalogi i nalogooblozhenie. - 2014. - 8. - C. 758-765. DOI: 10.7256/18128688.2014.8.12715. 